\title{
Responding to Negative Electronic Word of Mouth to Improve Purchase Intention
}

\author{
Robert Zinko ${ }^{1, * \mathbb{D}}$, Angela Patrick ${ }^{1}$, Christopher P. Furner ${ }^{2} \mathbb{D}$, Shalanda Gaines ${ }^{1}$, Mi Dya Kim ${ }^{1}$, Matthew Negri ${ }^{1}$, \\ Elsy Orellana ${ }^{1}$, Shelby Torres ${ }^{1}$ and Carmen Villarreal ${ }^{1}$ \\ 1 College of Business, Texas A\&M University-Central Texas, Killeen, TX 76549, USA; \\ abpatrick@tamuct.edu (A.P.); sg052@my.tamuct.edu (S.G.); mk021@my.tamuct.edu (M.D.K.); \\ mn017@my.tamuct.edu (M.N.); eo006@my.tamuct.edu (E.O.); st036@my.tamuct.edu (S.T.); \\ cv008@my.tamuct.edu (C.V.) \\ 2 College of Business, East Carolina University, Greenville, NC 27834, USA; furnerc@ecu.edu \\ * Correspondence: robert.zinko@tamuct.edu; Tel.: +1-254-501-5909
}

Citation: Zinko, R.; Patrick, A.; Furner, C.P.; Gaines, S.; Kim, M.D.; Negri, M.; Orellana, E.; Torres, S.; Villarreal, C. Responding to Negative Electronic Word of Mouth to Improve Purchase Intention. J. Theor. Appl. Electron. Commer. Res. 2021, 16, 1945-1959. https://doi.org/10.3390/ jtaer16060109

Academic Editor: José Ramón Saura

Received: 12 May 2021

Accepted: 23 June 2021

Published: 28 June 2021

Publisher's Note: MDPI stays neutral with regard to jurisdictional claims in published maps and institutional affiliations.

Copyright: (c) 2021 by the authors. Licensee MDPI, Basel, Switzerland. This article is an open access article distributed under the terms and conditions of the Creative Commons Attribution (CC BY) license (https:// creativecommons.org/licenses/by/ $4.0 /)$.

\begin{abstract}
Retailers have little control over what their customers say about their products and services online. Review platforms (e.g., Yelp and Travelocity) are rife with negativity, from both real customers with bad experiences and from fake reviews created by competitors. These negative reviews have been shown to influence the purchasing behavior of future consumers. Many platforms do afford companies some control by including them in the online conversation about their products or services. Crafting a response to a poor review which appeals to future consumers may mitigate some of the negative outcomes associated with that review. This study advances our knowledge of responding to negative reviews by adding to the growing body of research, using a simulation-based experiment to test the influence of three elements of a review response on purchase intention (i.e., an apology, an explanation and a pledge to correct the problem identified in the review). In doing so, the data show that purchase intention increases only when a response contains all three elements. Implications for e-commerce researchers and review platform developers are discussed.
\end{abstract}

Keywords: electronic word of mouth; NeWOM; online reviews; company responses; consumergenerated content

\section{Introduction}

Consumer behavior researchers have long investigated the tendency of customers to tap the experiences of others, in order to reduce uncertainty about the effectiveness of a product or service. Word of mouth (WOM) (i.e., the interpersonal communication about products and services between customers) has long been studied as a persuasive source of information for those who are searching (e.g., [1]). The WOM paradigm has been central to consumer behavior research for decades. Indeed, more than half a century ago, King and Summers [2] found that nearly two-thirds of those interviewed told others about products and services they had experienced, with consumers finding WOM to be more persuasive than corporate advertising. This finding is likely due to the fact that WOM is typically independent of marketers' selling intents and is thus considered to be more trustworthy and credible [3]. Although the influence of WOM on consumer outcomes have been extensively studied, the impact of this phenomenon has become even more important since the advent of the internet [4]; and in particular, online review platforms.

Electronic word of mouth (eWOM) is the online sharing of information about a product or service. Consumers who have had an experience with a product or service can use an online review platform (such as Tripadvisor.com) to share what they wish to about their experience, opinion, recommendations and even attach photos and videos to support their contentions. Since consumers who are considering a purchase are engaged in an optimization decision under substantial uncertainty [5], the experiences of other consumers 
contained in online reviews represent a valuable uncertainty reduction tool, which can influence the decision to purchase or not to purchase. Kiecker and Cowles [6] proposed that online posts written by individual consumers (i.e., those who held no corporate affiliations) would be received more favorably by readers than those posted by companies. These quazi-spontaneous posts, by private individuals, are seen as more objective, and therefore are more likely to be adopted by readers (i.e., Tsao and Hsieh [7] showed this to be the case, with an empirical examination of eWOM platforms). Likewise, Anastasiei, et al. [8] modeled the factors which cause a consumer to "adopt" information contained with an eWOM (i.e., the factors which lead a consumer to incorporate that information into their purchase decision) and found that source credibility is central to information adoption. They further showed that source credibility is determined by perceived source (i.e., reviewer) expertise and perceived argument quality. In summary, consumers view online product reviews posted by other customers (i.e., as opposed to companies) as having higher credibility, empathy and relevance. As such, these consumer-generated reviews are considered to be stronger determinants of purchase intention [3].

In service industries, where the ability to try before one buys is not possible and thus increases uncertainty, eWOM is an even more important uncertainty reduction tool [9]. Indeed, research has suggested that eWOM has a strong impact on a variety of aspects related to services, such as decision-making processes, satisfaction with services, and brand impressions (e.g., [10]). When contemplating products such as hotels (i.e., high risk purchases that cannot easily be returned), Carroll and Sileo [11] discovered that over 70\% of customers checked out others' reviews before booking a hotel.

Although positive reviews have been shown to affect consumer behavior, negative reviews seem to be of even more influential [12]. The consequences for companies are even more substantial since individuals are more likely to post about a negative experience than a positive one [13]. This is likely because negative reviews are a result of the following factors: venting negative feelings, concern for other consumers, social benefits, economic incentives, helping the company, advice seeking, exerting power on the company and positive self enhancement [14]. As such, many companies make an effort to respond to negative reviews when they appear on an online review platform, with the goal of countering the negative narrative and mitigating the influence of the negative review on the purchase intention of potential future customers [15]. Chang, et al. [16] have suggested that ignoring the negative comments of customers may result in future loss of business. Many scholars have advised managers to respond to negative reviews (e.g., $[17,18])$. Although these calls have existed for some time, "how" a company should respond to a review has not been empirically investigated. Reponses to negative eWOM can include a variety of content. Should a company apologize (i.e., or could this be seen as pandering)? Should an explanation be given (i.e., or could this be seen as attempting to place the blame elsewhere)? Should a company offer to correct the problem (i.e., or would just future offering of action be seen as in vain)? Although a stream of literature is developing regarding negative eWOM, existing research regarding responses is sparse. As such, this study attempts to address the following research question:

RQ: What is the most effective way for a company to respond to a negative online review?

This study seeks to identify which elements of responses to negative reviews influence consumer outcomes, particularly that of purchase intention. To do so, a simulation-based experiment is conducted in which subjects read a negative review, and are then randomly assigned to one of several experimental groups. Each group reads a different response to that review. The scenario presented consists of a negative hotel review. Although the motivations to share and seek-out eWOM have been shown to depend on the product or service in question (i.e., based on such characteristics as a product's function, status, or price; as well as a prospective customer's familiarity with the brand), research has shown that the effects of negative reviews is somewhat consistent across industries (i.e., negative WOM results in undesirable outcomes, such as decreased purchase intent (e.g., [19]). This study is 
conducted in the hospitality industry for several reasons. Hotels are experiential goods that are not returnable; as such, consumers do not have the ability to try before they buy, making the purchase high-risk. This leads consumers to evaluate such purchases systematically, making this context ideal for investigating the influence of situational characteristics which can be manipulated in scenarios [20].

This paper proceeds as follows: relevant literature related to negative eWOM and responses to eWOM are discussed. A model of purchase intention based on responses to negative reviews is then developed. In the methods section, this model is tested using a simulation-based experiment. Results are discussed, along with implications for research and practice, as well as future research. Summarizing remarks conclude the paper.

\section{Conceptual Model and Hypothesis Development}

\subsection{Negative eWOM}

Customers expressing dissatisfaction about a product or service is, "a process that emerges if a customer's service experience lies outside the acceptance zone during the service interaction and/or in the customer's evaluation of the value-in-use of the service" [21]. The discontentment with the product or services occurs when a customer's actual experience is lower than his or her expectations [22]. Cognitive dissonance theory suggests that upon having a negative experience, customers justify their dissatisfaction based upon a perceived discrepancy between customers' expectations (i.e., that were given to them by the organization providing the product or service) and actual performance [23]. Consumers reduce this cognitive dissonance by changing their attitude and/or sharing their response to that dissatisfaction with others [24]. This is consistent with the findings of Hennig-Thurau, Gwinner, Walsh and Gremler [14], who purported that negative eWOM often occurs when consumers wish to vent adverse feelings about a product, or have a concern for others (i.e., believe that others should be made aware of a poor product or service). Before online review platforms, the experiences of a dissatisfied customer could influence the purchase decisions of those whom they interact with in their daily life; however, with new technologies, a single dissatisfied customer can influence the decisions of millions of potential consumers [21].

Marketing researchers have long suggested that negative word of mouth (NeWOM) has a greater influence on consumers than does positive WOM (e.g., [25,26]). Likewise, the same effect occurs online (i.e., wherein NeWOM has a greater impact on consumers than that of positive eWOM) (e.g., [27]). That being said, using both lab experiments and consumer online reviews, Zhang, et al. [28] showed that consumers who searched for information about products associated with promotion consumption goals saw positive reviews to be more convincing than negative reviews (i.e., a positivity bias). Alternatively, when the products were associated with prevention consumption goals, they saw negative reviews as being more persuasive than positive reviews (i.e., a negativity bias).

Contrary to the tenants of the WOM paradigm, Berger, et al. [29] found that under some conditions, negative reviews can increase product awareness and thus sales. They note that when a product is relatively unknown, negative publicity tends to increase sales, but when a product is already popular, negative publicity hurts sales. Although Berger and colleagues argue that this has implications for NeWOM, they use New York Times reviews of books to test their hypothesis. Since consumers are unlikely to read online product reviews for products that they are not aware of or are already considering; and since New York Times book reviews are frequently ready by a variety of book consumers, it is unclear if this relationship would hold in the NeWOM context.

When considering the frequency of NeWOM, Kim and Gupta [30] found that a single negative review (i.e., among positive reviews) would tend to decrease a review's informative value, making a reader's evaluations less negative because a reader would attribute the negative emotions toward the product or service to the reviewer's irrational dispositions (i.e., and not the product itself). These authors imply that consumers engage in an effort to assess the veracity of the reviews before incorporating the information in those reviews 
into their decision process. Furner, et al. [31] note that when there are a large number of reviews, the amount of cognitive effort that the consumer is able to devote to uncertainty reduction will influence the extent to which they consider the information contained in the reviews. This causes them to rely on heuristics, satisficing and causing them to ignore or discount some information contained in the review.

One such approach to reducing the cognitive load associated with using eWOM to support purchase decisions is to focus on negative reviews. Research has shown that consumers tend to seek out negative reviews in order to mitigate their concerns about products or services that they are considering purchasing [32], while not reading all reviews. Since marketers are aware of the influence of negative reviews on purchase decisions, they often respond to these adverse reviews in order to mitigate their detrimental effect on the purchase decisions of future potential customers.

\subsection{Responding to $\mathrm{NeWOM}$}

The tendency for businesses to respond to NeWOM has substantially increased in the past decade [33]. An observational study by Xie, et al. [34] found that responses from a corporation to a negative review lead to an average increase of 0.235 stars in the TripAdvisor ratings of hotels.

As these companies became aware of the detrimental effects of NeWOM, they adopted strategies for responding. These approaches for responding to negative reviews have varied greatly. They include such aspects as improved services [35], aggression [36], apologies; and often, simply a neutral response, acknowledging the negative review [37]. By simply responding in a friendly and conciliatory way, the responder seeks to give the impression that the company is easy to work with and will endeavor to work with customers and ensure satisfaction, thus reducing hesitancy of future potential customers.

In exploring managerial responses, Sparks, et al. [38] manipulated four elements of organizational responses to NeWOM: source of response (not significant), voice of responder (a 'human tone' had better outcomes than a 'formal tone'), speed of response (faster was favorable), and action frame (whether a correction of the issue had already been performed, was not significant). This study stressed that although organizations have little control over the reviews of their products and services that appear online, they do have control over the response to those reviews. As such they highlighted the importance of understanding which elements of a response are effective in influencing consumer attitudes.

Although some research has investigated the type of responses to negative reviews that companies employ (e.g., [36]); with a few notable exceptions (e.g., [38]), little research has investigated the effectiveness of these responses (i.e., does responding to a negative review increase intention to purchase the product by consumers?). This study aims to address this gap by investigating the impact of a variety of response level factors that may mitigate the detrimental effect of negative reviews of a hotel on purchase intention.

\subsection{Hypothesis Development}

Research shows that organizations often leave a response to NeWOM which does not acknowledge the issue that was discussed in the review (e.g., "thank you for your review, we hope you will visit us again" as opposed to, "thank you for reporting this issue regarding our billing procedures. We have forwarded on the issue to our billing department so that we may correct the problem") [37]. Zhang and Vásquez attribute this to an assumption by the organization that any response is better than none at all.

This is consistent with the findings of Bhandari and Rodgers [39], who explored the influence of brand feedback (i.e., which they operationalized as responses to negative online reviews) and found that it had an indirect positive effect (i.e., through an increase in brand trust) on consumer purchase intention. Following this rationale, this study proposes that any sort of response (i.e., acknowledgement of an issue) will be better received by consumers than no response, since the consumers might interpret a lack of response that 
addresses the specific issue as patronizing (i.e., not taking the issue raised seriously) [40], and could serve as an indicator of a lack of concern for customer service, thus foreboding potential problems in the future.

Hypothesis 1 (H1). A neutral response to a negative review will result in a higher purchase intention than no response.

Furthermore, by providing an explanation of the issue that was identified in a negative review, it can be effective in mitigating the detrimental effect of the negative review if the reason is interpreted as believable, and not seen as an excuse [41]. By offering a reasonable explanation for the issue, the company signals that it understands the cause of the shortcoming, and recognizes that the shortcoming is problematic for its customers and is thus in a better position to mitigate the shortcoming in the future, and hoping that in ding so, the problem experienced by the customer will not be an issue for future customers. Indeed, Leung, Law, Van Hoof and Buhalis [18] encouraged managers to address negative reviews, explaining why the detrimental event occurred. Such responses have been shown to be more productive than a simple, generic response, as customers have found personalized responses to be more appreciated than generic ones [42].

eWOM researchers have supported a connection between specific responses (as opposed to general responses) to NeWOM and consumer outcomes. For example, Zhang, et al. [43] looked at 500 extant reviews of hotels on Travelocity.com. They found that a high level of personalized management response is associated with higher ratings. This study predicts that the relationships identified above will extend into the current context, and that consumers will interpret thoughtful and personalized explanations of issues identified in negative reviews as indicators that the organization is aware of issues. Furthermore, that the company seeks to address them and that the issues are less likely to affect future consumers, which should serve to increase purchase intention.

Hypothesis 2 (H2). A response to a negative review which contains a reason for the problem will result in higher purchase intention than a neutral response.

In the context of corporate disasters, a well-developed literature exploring the influence of apologies on consumer outcomes exists [44]. In the popular press, examples of apologies for high-level failings are abundant: from the Samsung Galaxy Note 7 phone battery explosion issue, to Wells Fargo opening accounts for customers without permission, to the Volkswagen emissions cheating scandal; examples of corporations apologizing are abundant. With the advent of the internet and social media, companies find themselves even more in the spotlight. While news cycles tend to move fast (i.e., allowing a disaster to move more quickly off the front page), social media facilitates the wide dissemination of negative news about products and services as well as the formation of shared negative emotional reactions to this news. Lee and Atkinson [45] recently explored the effectiveness of company apologies in response to a corporate crisis, and found that regardless of the company's involvement (i.e., minimal, or at the center of the disaster), an apology resulted in the best outcome.

In the realm of NeWOM, Kunz and Jahn [41] conducted a study which showed that apologies were more effective than "excuses". They found that even though the problem may not have been the fault of the organization, an apology would result in positive outcomes. Even if the fault does lie with the company, they still found that an apology was preferred. Similar findings have been reported by other researchers (e.g., [23]). Based on these findings, we contend that consumers will view an apology as a commitment to customer satisfaction, and as a willingness to emphasize with customers. As such, these actions will be seen as an indicator that the company will stand behind its products and services, which will reduce consumer concerns about poor outcomes, and increase their purchase intention. 
Hypothesis 3 (H3). A response to a negative review which contains an apology will result in higher purchase intention than a neutral response.

Thus far, this current study being presented has manipulated one response characteristic in each response (i.e., a response was either neutral, contained an explanation or contained an apology). This allows for the isolation of the effect of each response characteristic. However, real-world responses are not typically that simple, and often contain both an explanation and an apology. For example, Litvin and Hoffman [46] conducted a study in which a hotel manager responded to negative reviews. In the response, the hotel manager responded with acknowledgement of the issue, and also an apology. This resulted in a 15\% increase in a reader's intention to book the hotel (i.e., vs. no response by the management).

We have argued that an acknowledgment of the issue identified in a negative review signals an awareness of the problem, and thus that the organization has the ability to rectify the problem in the future. Although an apology indicates a sense of empathy for the customer and signals a willingness to take customers' needs into consideration, potentially resulting in better customer service. Each of these effects are predicted to increase purchase intention individually. Furthermore, this study predicts that when a response contains both an explanation and an apology, consumers will perceive both the sense of an ability to avoid the problem in the future and a commitment to customer satisfaction; thus reducing uncertainty and hesitancy, thereby increasing purchase intention even than a response which does not contain both components.

Hypothesis 4a (H4a). H4a: A response to a negative review which contains an apology and reason will result in a higher purchase intention than a response that contains only a reason.

Hypothesis $\mathbf{4 b} \mathbf{~} \mathbf{H} \mathbf{H b})$. A response to a negative review which contains an apology and a reason will result in a higher purchase intention than a response that contains only an apology.

Recovery strategies from a corporate disaster can be grouped into four categories: (1) no recovery, (2) technical recovery actions, (3) functional recovery actions, and (4) both technical and functional recovery actions [23]. Technical recoveries rectify damage done by the disaster and compensates those affected for their loss; while functional recovery often consists of an apology [47]. The more extensive the failure, the more likely that a technical recovery will be required (i.e., action over a simple apology) [23] in order to regain lost good will. This may be due to the fact that although apologies can be presented in place of taking actual action [48], research shows that at times, apologies are seen as meaningless [49]. Indeed, some view an apology as an attempt at damage control (i.e., as opposed to a true act of attrition, that would result in changes) [50]. This paper predicts that the corporate disaster recovery findings identified in this section will apply in NeWOM situations. Furthermore, when consumers see that a company has made attempts at a technical recovery (i.e., offering compensation) following NeWOM; it can be argued that they will be more comfortable doing business with this company. This is because the compensation can serve as a signal that that the company will not behave opportunistically; and because the consumer can expect compensation, should the product or service fail to meet their needs in the future. Thus, the consumer is expected to experience a perceived lesser purchase risk, which is expected to increase purchase intention.

Hypothesis 5a (H5a). A response to a negative review which contains a reason for the negative review, and states that action would be taken to rectify the issue will result in a higher purchase intention than a response that contains a reason alone.

Hypothesis $\mathbf{5 b} \mathbf{b} \mathbf{H} 5 \mathbf{b})$. A response to a negative review which contains a reason for the negative review, and states that action would be taken to rectify the issue will result in a higher purchase intention than a response that contains an apology alone. 
Hypotheses 1 through 5 highlight the importance of various components of a response to NeWOM. Each component has its own influence on consumer attitudes and beliefs, and all serve to reduce uncertainty and perceptions of purchase risk, thus increasing purchase intention. Specifically, an explanation of the reasons behind the failure or issue signals that the firm is aware of the problem and is capable of avoiding that problem in the future. Apologizing for the issue signals empathy and concern for customers, thus suggesting the potential for a positive customer service experience. Likewise, offering a correction signals that in the event of a failure of the product or service to meet the consumer's expectations, purchase risk is lower because the company may offer compensation to offset any problems. Since all these components of a response are not mutually exclusive, this paper predicts that responses which contain all three components will serve to reduce perceptions of purchase risk and increase purchase intention more so than responses which contain any single component (i.e., or combination of components).

Hypothesis 6a (H6a). Negative review responses that contain an apology, a reason for the negative review, and stating that action would be taken to rectify the problem will result in higher purchase intention than a response that contains a reason alone.

Hypothesis $\mathbf{6 b} \mathbf{( H 6 b ) . ~ N e g a t i v e ~ r e v i e w ~ r e s p o n s e s ~ t h a t ~ c o n t a i n ~ a n ~ a p o l o g y , ~ a ~ r e a s o n ~ f o r ~ t h e ~}$ negative review, and stating that action would be taken to rectify the problem will result in higher purchase intention than a response that contains an apology alone.

Hypothesis 6c (H6c). Negative review responses that contain an apology, a reason for the negative review, and stating that action would be taken to rectify the problem will result in higher purchase intention than a response that contains only an apology and a reason.

Hypothesis $6 \mathbf{d}(\mathbf{H 6 d})$. Negative review responses that contain an apology, a reason for the negative review, and stating that action would be taken to rectify the problem will result in a higher purchase intention than a response that only contains a reason and an action.

\section{Methods}

\subsection{Design of the Studies}

Web-based simulations were developed to test the hypothesis, following the protocol developed by Potts [51]. This approach to data collection is so frequently used by e-commerce researchers because it controls for variations in the environment, while allowing the researchers to manipulate variables of interest. As such, this approach is well established in both marketing and management (e.g., [52,53]). After answering standard demographic questions, study participants were directed to pretend that they intend to travel to Toronto, Canada, and are in need of hotel accommodation. Canada was chosen because the subjects all came from the United States. In order to minimize potential regional bias we chose a location that would not be of residence to any of the subjects, but would still be viewed as similar enough to the Uniters States [Hofstede dimentions rate the two countries to be quite similar: [54]) to allow for a reasonable knowledge of the industry by the participants.

Subjects were randomly assigned into seven groups. Individuals in each group were asked to read the same negative review, with one of the six different responses by the hotel (i.e., the seventh group read the review with no response). The scenarios were followed by a series of questions that were adapted from Furner, Zinko and Zhu [31], used to measure purchase intention (i.e., based on this review, how likely are you to rent a room in this hotel). These items were measured on a 7-point Likert scale. The participants were also asked the typical demographic questions. Finally, a manipulation check was performed to determine if the manipulations were effective (e.g., did consumers view the negative review as negative). 
The different responses were as follows: (1) no response, just the negative review (control); (2) a neutral response; (3) an apology response; (4) a response giving a reason for the issue identified in the negative review; (5) an apology and reason response, (6) a response giving a reason for the issue mentioned in the negative review, and stating that action would be taken to rectify the problem; and (7) an apology, a reason for the negative review, and stating that action would be taken to rectify the problem. See Appendix A for an example review.

\subsection{Measurement Instrument Development}

In order to ensure that the review responses that we developed accurately manipulated the construct of interest, a panel of three academic experts, as well as three industry experts, were asked to read the reviews and to categorize them based on the manipulations identified above [55]. All participants were able to classify each response with $100 \%$ accuracy. As such, the panel members were in agreement that the manipulations contained in the review responses consistently and comprehensively reflected the theoretical underpinnings of the constructs, thus establishing the face validity of the measurement tools.

\subsection{Research Participants}

Responses were gathered via Amazon's Mechanical Turn (MTurk). Each review was read by 60 unique respondents. As there were seven different responses (i.e., including a non-response review), the total number of subjects was 360 . The average age of the participant was 33, and $58 \%$ of the subjects were female. The average income reported was $\$ 36 \mathrm{~K}$. The use of MTurk data has been shown to be (1) more accurate and (2) often indistinguishable from many other sources of survey collection [56,57]. It is seen as more representative of the U.S. population than typical samples of convenience [58]. Finally, the collection of data from MTurk by other researchers has been published in leading scholarly journals in marketing, such as Journal of Marketing (e.g., $[59,60])$ and Journal of Marketing Research (e.g., [61,62]).

\subsection{Analysis and Results}

Data were analyzed using IBM SPSS Statistics version 27. Using purchase intention as a dependent variable, an ANOVA was conducted. Results support a significant difference in purchase intention between responses: $\mathrm{F}=6.772$, with a $p<0.01$ A univariate analysis with a Tukey's post hoc suggested significant mean differences for Apology, Reason and Action, vs. other responses. See Table 1 below:

Table 1. Means, Standard Deviation, and Test of Hypotheses.

\begin{tabular}{ccccc}
\hline Hypothesis & Response & Mean & Std. Dev & Mean Difference \\
\hline N/A & None & 1.97 & 1.90 & N/A \\
1 & Neutral (vs. None) & 2.86 & 1.89 & 0.89 \\
2 & Reason (vs. Neutral) & 2.5 & 1.76 & -0.36 \\
3 & Apology (vs. Neutral) & 2.82 & 1.60 & -0.04 \\
4a & Apology and Reason (vs. Reason) & 2.34 & 1.96 & -0.16 \\
4b & Apology and Reason (vs. Apology) & 2.34 & 1.96 & -0.48 \\
5a & Reason and Action (vs. Reason) & 2.59 & 1.74 & 0.09 \\
5b & Reason and Action (vs. Apology) & 2.59 & 1.74 & -0.23 \\
6a & Apology, Reason and Action (vs. Reason) & 4.03 & 1.97 & $1.53 *$ \\
6b & Apology, Reason and Action (vs. Apology) & 4.03 & 1.97 & $1.21^{*}$ \\
6c & Apology, Reason and Action (vs. Apology and Reason) & 4.03 & 1.97 & $1.69 *$ \\
6d & Apology, Reason and Action (vs. Reason and Action) & 4.03 & 1.97 & $1.44^{*}$ \\
\hline
\end{tabular}

* significant at $p<0.01$.

H1 was not supported as there was no significant difference between no response and a neutral response. H2 was not supported, as there was no significant difference between a 
response with a reason given, vs. a neutral response. Likewise, H3 was not supported, as a response involving an apology was not significantly different to a neutral response. Both $\mathrm{H} 4 \mathrm{a}$ and $\mathrm{H} 4 \mathrm{~b}$ were also not supported, as combining the reason with an apology did not significantly increase purchase intention. This was also the case with both H5a and H5b, as simply giving a reason and a pledge to fix the issue was not seen as any more positive than a giving a reason or an apology alone. However, H6 (a through d), which stated that an apology, a reason, and a promise to fix the issue, significantly increased purchase intention over all other responses.

\section{Discussion}

A wide body of research has demonstrated that the influence of eWOM on e-commerce outcomes is substantial, and more recent research suggests that the influence of NeWOM can be ruinous. Although empirical evidence indicates that positive reviews increase brand image, purchase intention and other consumer outcomes [63], negative reviews are more likely to have a greater impact on consumer outcomes [64]. Ye, et al. [65] found evidence to support that a $10 \%$ improvement in reviewers' rating can increase sales by $4.4 \%$, and a $10 \%$ decrease in ratings can decrease sales by $2.8 \%$. Since organizations have a very limited control over what customers say about their products in online reviews, they must focus on influencing the things that they can control. This highlights the importance of developing high-quality products, focusing on service quality and improving customer satisfaction. Even with substantial investment in these efforts, negative reviews can still bring down sales. Since online review platforms often give companies the opportunity to reply to reviews, they can serve as an opportunity to mitigate the damage caused by NeWOM. This study sought to understand which response strategies are effective at facilitating purchase intention. Specifically, responses that included all components (an explanation, an apology, and a commitment to fix the issue) were found to influence purchase intention; however, responses that included any of these components, individually, did not significantly improve purchase intention in our sample.

\subsection{Research Implications}

These findings carry significant implications for researchers. According to Keith, et al. [66] research on information systems typically trail practice, with models and paradigms being developed and tested only after an information system has been in use for some time. This is particularly true in the e-commerce context [5]. While online review platforms emerged in February of 1996 with e-bay's Feedback Forum [67], it was not until the mid-2000s that marketing and information system researchers began publishing studies that evaluated the impact of these reviews on consumer behavior [68] (e.g.). Researchers eventually adopted a well-established paradigm, WOM to the online review context, thus creating a new research area (eWOM) which has been flourishing.

Within eWOM, researchers have modeled and tested the influence of review, reviewer, product/service and consumer characteristics on consumer outcomes with the goal of better understanding consumer behavior in the e-commerce context, which is dynamic and rapidly evolving [69]. Early eWOM research only considered the influence of positive reviews, although Ho-Dac, et al. [70] provided evidence that consumers specifically seek out negative reviews. While research on the impact of negative reviews is emerging, a major gap exists in the literature regarding the influence of responses to negative reviews on consumer behavior. Companies have control over how they respond to negative reviews, and our study provides evidence that consumer behavior is influenced by these responses. This implies that researchers have the potential to augment our understanding of consumer behavior by understanding the elements of effective responses to reviews, and the circumstances under which those responses are most effective.

This study is among the early studies to explore specific responses to NeWOM in a controlled environment, and found that the detrimental impact of negative reviews on consumer intentions can be mitigated if the response contains certain elements. This 
represents a substantial contribution to the evolving eWOM paradigm, and suggested new areas for exploration, which are outlined in the future research subsection below.

Finally, this research aids in clarifying our current understanding of responding to NeWOM. Indeed, studies exist that discuss the advantage of offering an apology, but does not clarify what that apology entails (e.g., [41]). Our research shows that the apology needs to be robust (i.e., and needs to include an explanation as well as a plan to correct the situation). In building upon the fine work done in these earlier studies, we are able to further clarify the best type of response to NeWOM.

\subsection{Practical Implications}

These findings also carry implications for brand holders and retailers who operate in the e-commerce marketplace, and whose products and services are reviewed in online review platforms. The influence of online reviews on e-commerce outcomes is well documented and well understood by practitioners. Online review platforms seek to maximize sales while minimizing returns, by manipulating the order in which reviews are presented to consumers [19]. Many platforms provide consumer accounts which track consumer characteristics and employ smart algorithms to manipulate review order based on the information in the consumer profile. The findings of the current study suggest that when a consumer is seeking out negative reviews, the review platform should prioritize those negative reviews in which the company has responded, and specifically those responses which include all three of the following elements: an explanation, an apology, and a pledge to rectify the issue. By prioritizing these reviews, findings suggest that the platform can increase purchase intention for future researchers.

\subsection{Limitations}

Like most single-method studies, our findings are limited by the scope of our data collection. Although NeWOM has been shown to affect many industries (e.g., [19,71]), the current data collected only included hotels. We selected this industry because hotels are considered to be high risk purchases that are not returnable and without the ability to try before one buys, which is consistent with the goals of our study. Further investigation may be needed, in order to increase the generalizability of our findings. Next, our data came from American subjects. As such, the findings may not be generalizable to populations which differ in terms of cultural, particularly norms regarding vacations. Future studies may expand the sampling pool to include more diverse subjects. Finally, this study did not include the possibility of compensation in the responses to negative reviews. It could be argued that an offer of compensation may be more effective than an apology, explanation, and promise of action. As this study is an early step in understanding the influence of responses to negative reviews on consumer behavior, there remains a great deal of room for exploration in this domain. A few suggestions for future research are presented in the following subsection.

\subsection{Future Research}

Although the findings of this study represent an important step toward understanding how responses to negative reviews influence consumer attitudes, there remains quite a bit of room for research in this domain. A variety of response approaches remain unexplored, and can be studied by developing simulated review/response scenarios in which response characteristics are manipulated. Specifically, to what extent does offering compensation in response to a negative review influence the perceptions of consumers? Does the amount of compensation need to be congruent with the severity of the service failure outlined in the review (i.e., when the service failure is most substantial, does offering the same level of compensation improve consumer outcomes, or is more compensation necessary to improve those outcomes)? Finally, if the information quality and information load of online reviews have been shown to influence purchase intention [31], do the information quality and information load of responses to reviews also influence consumer outcomes? 
Beyond exploring response characteristics, the setting of the transaction being reviewed may influence consumer construal of the response. For example, consumers may have different expectations of nationally recognized branded retailers than they do for local, smaller businesses [72]. Do these differences in expectations result in differences in consumer outcomes based on responses to negative reviews? Furthermore, this paper argues that the detrimental effects of negative reviews are substantial, and that by responding, companies can mitigate some of those detrimental effects. It may also be possible that responses to positive reviews may influence consumer behavior in a reinforcing manner. This represents another avenue for exploration. Additionally, there has been an uptick in research regarding the motivation behind individuals searching for online reviews (e.g., [73,74]). Indeed, as we gather more information about the characteristics of those who utilized eWOM for purchases, we can better research the ability to tailor responses to those individuals.

Finally, fake reviews (i.e., reviews written by an entity with an interest in the success or failure of a product or service) as well as reviews that are done by real consumers, but customers with finical motivation [75]; are another eWOM phenomenon that has been extensively studied. Are there elements of responses to reviews which a consumer may believe to be fake that can influence purchase intention? Is it possible for a company to raise suspicion that a review may be fake in their response to the review, thus leading the consumer to discount the negativity in the review? How do consumers react when a company attempts to do this and succeeds, and when they fail to convince the consumer that the review is fake?

\section{Conclusions}

Online reviews have a substantial impact on the behavior of hundreds of millions of consumers daily, and billions of dollars of economic activity annually [67]. As such, the influence of online reviews on consumer behavior has been widely studied by researchers. While early studies focused on the positive effects of positive reviews, the influence of negative reviews has recently gained traction among eWOM researchers. This study underscores the attention that consumers devote to negative reviews to highlight the potential of responses to negative reviews as a mechanism to influence consumer behavior, and specifically finds that when a response contains an apology, and an explanation, and a pledge to rectify the issue identified in the review, purchase intention for future consumers can increase. This represents an early step in the exploration of the influence of negative review responses, which are one of the few tools that companies can control in the eWOM environment.

Author Contributions: R.Z.: Conceptualization, methods, validation, formal analysis, investigation, resources, writing — original draft preparation, writing — review and editing. A.P.: Methods, validation, data curation, writing — review and editing. C.P.F.: Conceptualization, resources, writingreview and editing. A.P.: Formal analysis, writing-review and editing. S.G., M.D.K., M.N., E.O., S.T., and C.V.: Conceptualization, writing—original draft preparation. All authors have read and agreed to the published version of the manuscript.

Funding: This research received no external funding.

Institutional Review Board Statement: The study was conducted according to the guidelines of the Declaration of Helsinki, and approved by the Institutional Review Board (or Ethics Committee) of Texas A\&M University—Central Texas (protocol code 2018120001, approved: 12/8/2018).

Informed Consent Statement: Informed consent was obtained from all subjects involved in the study.

Data Availability Statement: The data presented in this study are available on request from the corresponding author.

Conflicts of Interest: The authors declare no conflict of interest. 


\section{Appendix A}

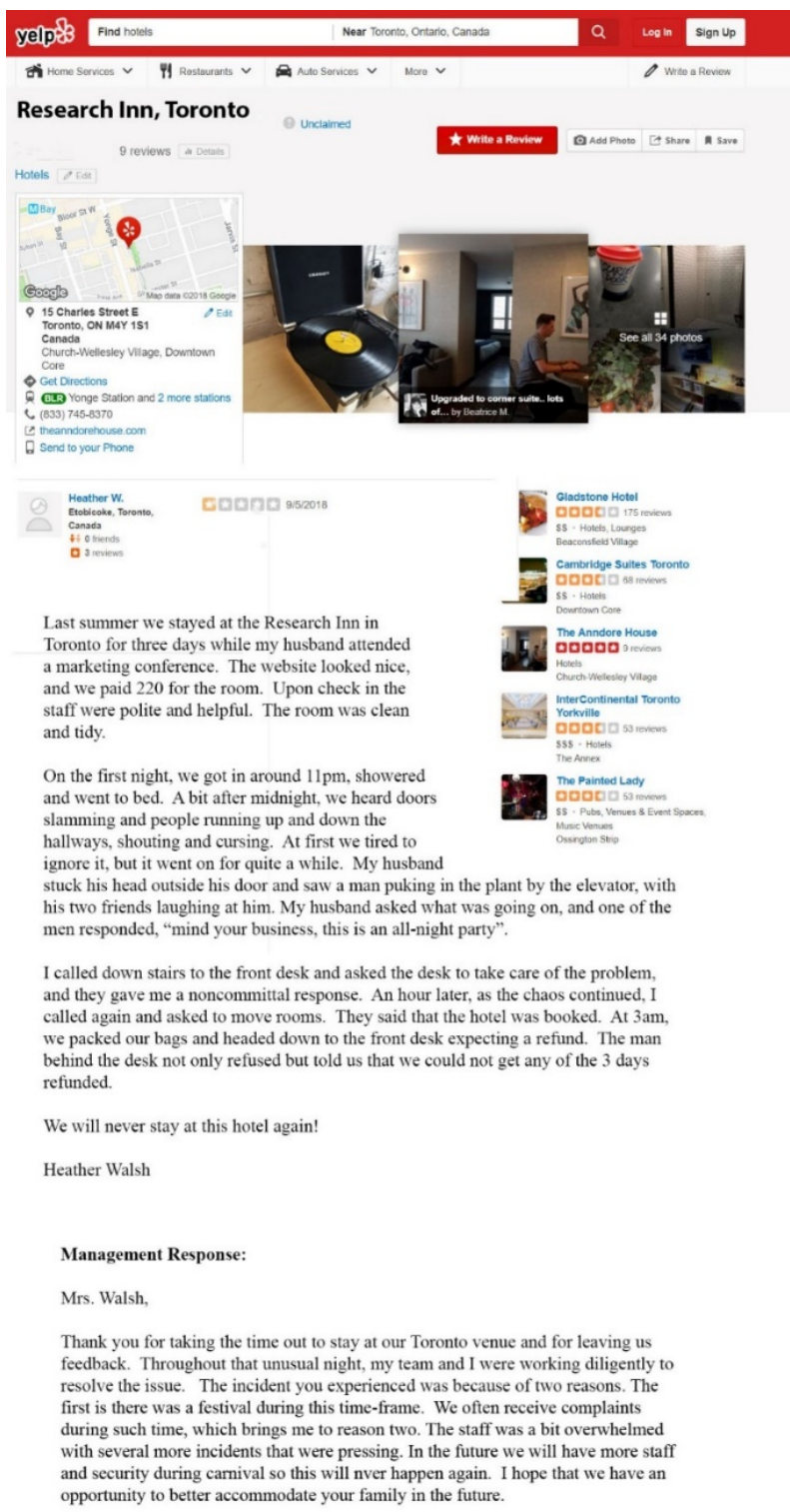

Figure A1. Review with reason and apology.

\section{References}

1. Arndt, J. Role of product-related conversations in the diffusion of a new product. J. Mark. Res. 1967, 4, 291-295. [CrossRef]

2. King, C.W.; Summers, J.O. Technology, innovation and consumer decision making. In Proceedings of the Changing Marketing Systems, Chicago, 2012; pp. 63-68.

3. Bickart, B.; Schindler, R.M. Internet forums as influential sources of consumer information. J. Interact. Mark. 2001, 15, 31-40. [CrossRef]

4. Dellarocas, C. The digitization of word of mouth: Promise and challenges of online feedback mechanisms. Manag. Sci. 2003, 49, 1407-1424. [CrossRef]

5. Furner, C.P.; Racherla, P.; Zhu, Z. A multinational study of espoused national cultural and review characteristics in the formation of trust in online product reviews. Int. J. Serv. Technol. Manag. 12 2014, 20, 14-30. [CrossRef]

6. Kiecker, P.; Cowles, D. Interpersonal communication and personal influence on the Internet: A framework for examining online word-of-mouth. J. Euromark. 2002, 11, 71-88. [CrossRef]

7. Tsao, W.-C.; Hsieh, M.-T. eWOM persuasiveness: Do eWOM platforms and product type matter? Electron. Commer. Res. 2015, 15, 509-541. [CrossRef]

8. Anastasiei, B.; Dospinescu, N.; Dospinescu, O. Understanding the Adoption of Incentivized Word-of-Mouth in the Online Environment. J. Theor. Appl. Electron. Commer. Res. 2021, 16, 992-1007. [CrossRef] 
9. Golmohammadi, A.; Mattila, A.S.; Gauri, D.K. Negative online reviews and consumers' service consumption. J. Bus. Res. 2020, 116, 27-36. [CrossRef]

10. Hogreve, J.; Bilstein, N.; Hoerner, K. Service recovery on stage: Effects of social media recovery on virtually present others. J. Serv. Res. 2019, 22, 421-439. [CrossRef]

11. Carroll, B.; Sileo, L. Online Travel Agencies: More than a Distribution Channel; PhocusWright: New York, NY, USA, 2014.

12. Salehi-Esfahani, S.; Ravichandran, S.; Israeli, A.; Bolden, E., III. Investigating information adoption tendencies based on restaurants' user-generated content utilizing a modified information adoption model. J. Hosp. Mark. Manag. 2016, 25, 925-953. [CrossRef]

13. Koh, N.S.; Hu, N.; Clemons, E.K. Do online reviews reflect a product's true perceived quality? An investigation of online movie reviews across cultures. Electron. Commer. Res. Appl. 2010, 9, 374-385. [CrossRef]

14. Hennig-Thurau, T.; Gwinner, K.P.; Walsh, G.; Gremler, D.D. Electronic word-of-mouth via consumer-opinion platforms: What motivates consumers to articulate themselves on the internet? J. Interact. Mark. 2004, 18, 38-52. [CrossRef]

15. Bambauer-Sachse, S.; Mangold, S. Brand equity dilution through negative online word-of-mouth communication. J. Retail. Consum. Serv. 2011, 18, 38-45. [CrossRef]

16. Chang, H.H.; Lai, M.-K.; Hsu, C.-H. Recovery of online service: Perceived justice and transaction frequency. Comput. Hum. Behav. 2012, 28, 2199-2208. [CrossRef]

17. Wei, W.; Miao, L.; Huang, Z. Customer engagement behaviors and hotel responses. Int. J. Hosp. Manag. 2013, 33, 316-330. [CrossRef]

18. Leung, D.; Law, R.; Van Hoof, H.; Buhalis, D. Social media in tourism and hospitality: A literature review. J. Travel Tour. Mark. 2013, 30, 3-22. [CrossRef]

19. Zinko, R.; Furner, C.P.; Burgh-Woodman, H.d.; Johnson, P.; Sluhan, A. The Addition of Images to eWOM in the Travel Industry: An Examination of Hotels, Cruise Ships and Fast Food Reviews. J. Theor. Appl. Electron. Commer. Res. 2021, 16, 525-541. [CrossRef]

20. Zinko, R.; Stolk, P.; Furner, Z.; Almond, B. A picture is worth a thousand words: How images influence information quality and information load in online reviews. Electron. Mark. 2020, 30, 775-789. [CrossRef]

21. Tronvoll, B. Negative emotions and their effect on customer complaint behaviour. J. Serv. Manag. 2011, 22, 111-134. [CrossRef]

22. Hussain, S.; Ahmed, W.; Jafar, R.M.S.; Rabnawaz, A.; Jianzhou, Y. eWOM source credibility, perceived risk and food product customer's information adoption. Comput. Hum. Behav. 2017, 66, 96-102. [CrossRef]

23. Israeli, A.A.; Lee, S.A.; Bolden, E.C., III. The impact of escalating service failures and internet addiction behavior on young and older customers' negative eWOM. J. Hosp. Tour. Manag. 2019, 39, 150-157. [CrossRef]

24. Ng, S.; David, M.E.; Dagger, T.S. Generating positive word-of-mouth in the service experience. Manag. Serv. Qual. 2011, 21, 133-151. [CrossRef]

25. Herr, P.M.; Kardes, F.R.; Kim, J. Effects of word-of-mouth and product-attribute information on persuasion: An accessibilitydiagnosticity perspective. J. Consum. Res. 1991, 17, 454-462. [CrossRef]

26. Mizerski, R.W. An attribution explanation of the disproportionate influence of unfavorable information. J. Consum. Res. 1982, 9, 301-310. [CrossRef]

27. Park, C.; Lee, T.M. Information direction, website reputation and eWOM effect: A moderating role of product type. J. Bus. Res. 2009, 62, 61-67. [CrossRef]

28. Zhang, J.Q.; Craciun, G.; Shin, D. When does electronic word-of-mouth matter? A study of consumer product reviews. J. Bus. Res. 2010, 63, 1336-1341. [CrossRef]

29. Berger, J.; Sorensen, A.T.; Rasmussen, S.J. Positive effects of negative publicity: When negative reviews increase sales. Mark. Sci. 2010, 29, 815-827. [CrossRef]

30. Kim, J.; Gupta, P. Emotional expressions in online user reviews: How they influence consumers' product evaluations. J. Bus. Res. 2012, 65, 985-992. [CrossRef]

31. Furner, C.P.; Zinko, R.; Zhu, Z. Electronic word-of-mouth and information overload in an experiential service industry. J. Serv. Theory Pract. 2016, 26, 788-810. [CrossRef]

32. Lee, J.; Park, D.-H.; Han, I. The effect of negative online consumer reviews on product attitude: An information processing view. Electron. Commer. Res. Appl. 2008, 7, 341-352. [CrossRef]

33. Sparks, B.A.; Bradley, G.L. A “Triple A” typology of responding to negative consumer-generated online reviews. J. Hosp. Tour. Res. 2017, 41, 719-745. [CrossRef]

34. Xie, K.L.; Zhang, Z.; Zhang, Z.; Singh, A.; Lee, S.K. Effects of managerial response on consumer eWOM and hotel performance. Int. J. Contemp. Hosp. Manag. 2016, 28, 2013-2034. [CrossRef]

35. Melián-González, S.; Bulchand-Gidumal, J.; González López-Valcárcel, B. Online customer reviews of hotels: As participation increases, better evaluation is obtained. Cornell Hosp. Q. 2013, 54, 274-283. [CrossRef]

36. Napolitano, A. Image Repair or Self-Destruction? A Genre and Corpus-Assisted Discourse Analysis of Restaurants' Responses to Online Complaints. Crit. Approaches Discourse Anal. Discip. 2018, 10, 135-153.

37. Zhang, Y.; Vásquez, C. Hotel' responses to online reviews: Managing consumer dissatisfaction. Discourse Context Media 2014, 6, 54-64. [CrossRef]

38. Sparks, B.A.; So, K.K.F.; Bradley, G.L. Responding to negative online reviews: The effects of hotel responses on customer inferences of trust and concern. Tour. Manag. 2016, 53, 74-85. [CrossRef] 
39. Bhandari, M.; Rodgers, S. What does the brand say? Effects of brand feedback to negative eWOM on brand trust and purchase intentions. Int. J. Advert. 2018, 37, 125-141. [CrossRef]

40. Harwood, J.; Ryan, E.B.; Giles, H.; Tysoski, S. Evaluations of patronizing speech and three response styles in a non-serviceproviding context. J. Appl. Commun. Res. 1997, 25, 170-195. [CrossRef]

41. Kunz, W.H.; Jahn, B. Serving in an online world: How to react on negative electronic word-of-mouth. In Proceedings of the Marketing in the Socially-Networked World: Challenges of Emerging, Stagnant, and Resurgent Markets, Chicago, IL, USA, 17-19 August 2012.

42. Jakic, A.; Wagner, M.O.; Meyer, A. The impact of language style accommodation during social media interactions on brand trust. J. Serv. Manag. 2017, 28, 414-421. [CrossRef]

43. Zhang, X.; Qiao, S.; Yang, Y.; Zhang, Z. Exploring the impact of personalized management responses on tourists' satisfaction: A topic matching perspective. Tour. Manag. 2020, 76, 103953. [CrossRef]

44. Patel, A.; Reinsch, L. Companies can apologize: Corporate apologies and legal liability. Bus. Commun. Q. 2003, 66, 9-25. [CrossRef]

45. Lee, S.Y.; Atkinson, L. Never easy to say "sorry": Exploring the interplay of crisis involvement, brand image, and message appeal in developing effective corporate apologies. Public Relat. Rev. 2019, 45, 178-188. [CrossRef]

46. Litvin, S.W.; Hoffman, L.M. Responses to consumer-generated media in the hospitality marketplace: An empirical study. J. Vacat. Mark. 2012, 18, 135-145. [CrossRef]

47. Ally, S.; Karpinski, A.C.; Israeli, A.A. Customer behavioural analysis: The impact of internet addiction, interpersonal competencies and service orientation on customers' online complaint behaviour. Res. Hosp. Manag. 2020, 10, 97-105.

48. Mills, N. The new culture of apology. Dissent 2001, 48, 113-116.

49. Thompson, J. Apology, justice, and respect: A critical defense of political apology. In Proceedings of the ustralian Association for Professional and Applied Ethics 12th Annual Conference, Adelaide, Australia, 28-30 September 2005; pp. 31-44.

50. Fuchs-Burnett, T. Mass public corporate apology. Disput. Resolut. J. 2002, 57, 26-35.

51. Potts, C. Using schematic scenarios to understand user needs. In Proceedings of the 1st Conference on Designing Interactive Systems: Processes, Practices, Methods, \& Techniques; pp. 247-256.

52. Hui, K.-L.; Teo, H.H.; Lee, S.-Y.T. The value of privacy assurance: An exploratory field experiment. Mis Q. 2007, 31, 19-33. [CrossRef]

53. Hunt, S.D.; Vitell, S. A general theory of marketing ethics. J. Macromark. 1986, 6, 5-16. [CrossRef]

54. Grunig, L.A.; Grunig, J.E.; Vercic, D. Are the IABC's excellence principles generic? Comparing Slovenia and the United States, the United Kingdom and Canada. J. Commun. Manag. 1998, 2, 335-356. [CrossRef]

55. Liu, Y.; Ferris, G.R.; Zinko, R.; Perrewé, P.L.; Weitz, B.; Xu, J. Dispositional antecedents and outcomes of political skill in organizations: A four-study investigation with convergence. J. Vocat. Behav. 2007, 71, 146-165. [CrossRef]

56. Casler, K.; Bickel, L.; Hackett, E. Separate but equal? A comparison of participants and data gathered via Amazon's MTurk, social media, and face-to-face behavioral testing. Comput. Hum. Behav. 2013, 29, 2156-2160. [CrossRef]

57. Paolacci, G.; Chandler, J.; Ipeirotis, P.G. Running experiments on amazon mechanical turk. Judgm. Decis. Mak. 2010, 5, 411-419.

58. Berinsky, A.J.; Huber, G.A.; Lenz, G.S. Evaluating online labor markets for experimental research: Amazon.com's Mechanical Turk. Political Anal. 2012, 20,351-368. [CrossRef]

59. Luo, L.; Toubia, O. Improving online idea generation platforms and customizing the task structure on the basis of consumers domain-specific knowledge. J. Mark. 2015, 79, 100-114. [CrossRef]

60. Roggeveen, A.L.; Grewal, D.; Townsend, C.; Krishnan, R. The impact of dynamic presentation format on consumer preferences for hedonic products and services. J. Mark. 2015, 79, 34-49. [CrossRef]

61. Laran, J.; Janiszewski, C.; Salerno, A. Exploring the differences between conscious and unconscious goal pursuit. J. Mark. Res. 2016, 53, 442-458. [CrossRef]

62. Yoon, S.; Kim, H.C. Keeping the American Dream Alive: The Interactive Effect of Perceived Economic Mobility and Materialism on Impulsive Spending. J. Mark. Res. 2016, 52, 759-772. [CrossRef]

63. Krishnamurthy, A.; Kumar, S.R. Electronic word-of-mouth and the brand image: Exploring the moderating role of involvement through a consumer expectations lens. J. Retail. Consum. Serv. 2018, 43, 149-156. [CrossRef]

64. Xie, H.J.; Miao, L.; Kuo, P.-J.; Lee, B.-Y. Consumers' responses to ambivalent online hotel reviews: The role of perceived source credibility and pre-decisional disposition. Int. J. Hosp. Manag. 2011, 30, 178-183.

65. Ye, Q.; Law, R.; Gu, B. The impact of online user reviews on hotel room sales. Int. J. Hosp. Manag. 2009, 28, 180-182. [CrossRef]

66. Keith, M.; Babb, J.; Furner, C.; Abdullat, A. The role of mobile self-efficacy in the adoption of geospatially-aware applications: An empirical analysis of iPhone Users. In Proceedings of the 44th Hawaii International Conference on System Science, Honolulu, HI, USA, 20-22 January 2012.

67. Sprague, D.J. The History of Online Reviews and How They Have Evolved. Available online: https:/ /5stars.shopperapproved. com/the-history-and-evolution-of-online-reviews / (accessed on 10 May 2021).

68. Chen, P.-Y.; Wu, S.-y.; Yoon, J. The impact of online recommendations and consumer feedback on sales. In Proceedings of the ICIS 2004 Proceedings, Washington, DC, USA, 12-15 December 2004; p. 58.

69. Tran, T.P.; Furner, C.P.; Albinsson, P.A. Understanding drivers and outcomes of brand attachment in mobile branded apps. J. Consum. Mark. 2021, 38, 113-124. [CrossRef] 
70. Ho-Dac, N.N.; Carson, S.J.; Moore, W.L. The effects of positive and negative online customer reviews: Do brand strength and category maturity matter? J. Mark. 2013, 77, 37-53. [CrossRef]

71. Lievonen, M.; Luoma-aho, V.; Hätönen, H. What Drives Negative Electronic Word-of-Mouth Online? In Proceedings of the Annual International Conference on Journalism \& Mass Communications.

72. Bronnenberg, B.J.; Dhar, S.K.; Dubé, J.-P. Consumer packaged goods in the United States: National brands, local branding. J. Mark. Res. 2007, 44, 4-13. [CrossRef]

73. Mikalef, P.; Giannakos, M.; Pateli, A. Shopping and word-of-mouth intentions on social media. J. Theor. Appl. Electron. Commer. Res. 2013, 8, 17-34. [CrossRef]

74. Choi, J.H.; Scott, J.E. Electronic word of mouth and knowledge sharing on social network sites: A social capital perspective. J. Theor. Appl. Electron. Commer. Res. 2013, 8, 69-82. [CrossRef]

75. Hansen, S.S.; Lee, J.K. What drives consumers to pass along marketer-generated eWOM in social network games? Social and game factors in play. J. Theor. Appl. Electron. Commer. Res. 2013, 8, 53-68. 